\title{
EQUALIZAÇÃO E SEGMENTAÇÃO DE IMAGENS USANDO INFORMAÇÕES DE CORES
}

\section{EQUALIZING AND SEGMENTING IMAGES USING COLOR INFORMATION}

Marcos Vinicius Inocêncio, Almir Olivette Artero, Danilo Medeiros Eler, Francisco Assis da Silva, Danillo Roberto Pereira

Universidade Estadual Paulista - UNESP, Presidente Prudente, SP. Universidade do Oeste Paulista-UNOESTE, Presidente Prudente, SP.

E-mail: $\quad$ marcos.inocencio13@gmail.com; almir.artero@unesp.br; danilo.eler@unesp.br; chico@unoeste.br; danilopereira@unoeste.br

RESUMO - Em geral, as técnicas de processamento digital de imagens são aplicadas em imagens em tons de cinza, apesar da grande disponibilidade de imagens coloridas. Embora a literatura da área sempre dedique algum tópico ao estudo do processamento usando cores e, afirme que todo o processamento com as imagens em tons de cinza pode ser estendido às imagens coloridas, tratando os três canais de cores, na prática, o processamento de imagens coloridas ainda é muito pouco explorado. Assim, este trabalho apresenta algumas propostas para usar a informação de cores na segmentação (usando um detector de bordas) e na equalização de imagens (apresenta uma proposta que evita a conversão entre modelos de cores). Os resultados obtidos são avaliados através de uma análise qualitativa e quantitativa das imagens obtidas com o processamento tradicional, usando apenas imagens em tons de cinzas e das imagens obtidas usando as estratégias propostas. Os resultados mostram que, diferentes maneiras de se combinar as informações de cores durante o processo levam a resultados muito diferentes entre si.

Palavras-chave: Processamento de imagens coloridas; Equalização; Segmentação.

ABSTRACT - Digital image processing techniques are generally applied to grayscale images, despite the large availability of color images. Although the literature always devotes some topic to the study of processing using colors and, they claim that all processing with grayscale images can be extended to color images, using the three color channels, in practice, the processing of color images still it is very little explored. Thus, this work presents some proposals for using color information in segmentation (using an edge detector) and in image equalization (presents a proposal that avoids the conversion between color models). The results obtained are evaluated through a qualitative and quantitative analysis of the images obtained with traditional 
processing, using only gray tones and images obtained using the proposed strategies. The results show that different ways of combining color information during the process lead to very different results.

Keywords: Color image processing; Equalization; Segmentation.

\section{INTRODUÇÃO}

A área de processamento digital de imagens vem apresentando um grande avanço nos últimos anos, e suas aplicações se estendem há várias outras áreas como: Medicina (MCAULIFFE et al., 2001), Sensoriamento Remoto (CAMPBELL; WYNNE, 2011), Robótica (CORKE, 2017), Segurança (GAVRILOVA; MONWAR, 2013), Cartografia (DENÈGRE, 1994), entre muitas outras [Marques Filho et al. 1999]. De fato, na área médica, o uso de imagens obtidas em exames de Ultra-Som, Ressonância Magnética e Tomografia Computadorizada permitem aos profissionais da saúde fazer diagnósticos muito precisos e, sem grandes incômodos aos pacientes. Em sensoriamento remoto, 0 uso de imagens obtidas a partir de câmeras embarcadas em satélites tem sido decisivo para analisar a superfície do planeta, permitindo a detecção de desmatamentos, áreas de mineração, etc. Em robótica, o uso de câmeras tem sido proposto para implementar sistemas de visão computacional, destinados à navegação dos dispositivos robóticos (atualmente, com ampla aplicação em veículos autônomos). $\mathrm{Na}$ área de segurança, o reconhecimento de faces humanas é uma das aplicações muito usadas atualmente, objetivando detectar a presença de pessoas procuradas pela justiça em locais de grande circulação, como aeroportos e outros locais. Na Cartografia busca-se desenvolver técnicas que sejam capazes de identificar os objetos presentes em imagens aéreas (edificações, ruas, etc.) e, em geral, isto é feito encontrando os limites que definem tais objetos, através de uma detecção de bordas. Por causa da grande quantidade de imagens que são capturadas por um veículo autônomo e, da necessidade de se processá-las de modo totalmente automático, para se tomar decisões em espaços de tempo muito curtos, para se fazer as correções no trajeto do veículo, o processamento destas imagens continua sendo um grande desafio.

Em geral, o processamento das imagens segue alguns passos bem conhecidos, que são: 1) Aquisição das imagens, utilizando câmeras fotográficas (atualmente, com predominância de modelos digitais); 2) Pré-processamento, objetivando a remoção de ruídos e o excesso de informações, que podem dificultar as demais etapas (usualmente, obtidos com a aplicação de filtros de suavização da imagem), correções de iluminação (Equalização e outras correções baseadas em histogramas de níveis de cinza); 3) Segmentação, objetivando identificar os objetos existentes na imagem (rotineiramente, implementada através da identificação de linhas de borda e crescimento de regiões); 4) Representação e Descrição, objetivando extrair medidas dos objetos encontrados, de modo a diferenciálos; 5) Reconhecimento e Interpretação, objetivando uma identificação exata dos objetos presentes nas imagens.

Apesar da grande disponibilidade de câmeras coloridas nos dias atuais, as técnicas de processamento de imagens são, em sua grande maioria, aplicadas em imagens em tons de cinza. Entretanto, a conversão das imagens coloridas em imagens em tons de cinza gera uma perda de informação muito severa, que contribui para a dificuldade em se obter sistemas automáticos eficazes. Por exemplo, no caso de detecção de falhas em plantações, o uso da cor verde é fundamental no processo (CRULHAS et al., 2018). Embora a bibliografia recomende $\mathrm{o}$ uso de informações de cores no processamento das imagens coloridas, os diferentes modos como estas informações podem ser tratadas continua sendo pouco explorado. Deste 
modo, existem poucos estudos apontando as vantagens e desvantagens, que podem ser obtidas com diferentes combinações do uso destas informações de cores, usando diferentes modelos de core. Embora existam vários trabalhos abordando o processamento digital de imagens coloridas, sugerindo a aplicação destas operações sobre as componentes de cores usadas nas imagens, há poucos estudos das vantagens $\mathrm{e}$ desvantagens, que podem ser obtidas com diferentes combinações do uso destes componentes de cores, por exemplo, apontando situações na qual, com a utilização de certas combinações de componentes de cores, os resultados são melhores em relação a outras combinações.

Este trabalho propõe avaliar o impacto do uso de informações de cores em um processo de equalização de imagens e durante uma etapa de segmentação usando métodos de detecção de bordas. Os resultados dos métodos propostos são comparados com os resultados dos métodos tradicionais (usando o processamento com imagens em tons de cinza), implementados com o OpenCV, que é uma biblioteca de processamento de imagens largamente utilizada pela comunidade científica. Além de uma análise visual (qualitativa) dos resultados, também é apresentada uma análise quantitativa dos resultados.

As demais seções deste trabalho estão organizadas da seguinte maneira: a Seção 2 descreve as operações de processamento digital de imagens abordadas; a Seção 3 apresenta alguns trabalhos relacionados ao processamento digital de imagens coloridas e também na análise de desempenho de detectores de bordas; a Seção 4 apresenta algumas propostas para combinar as informações de cores na equalização e na detecção de bordas (segmentação); a Seção 5 apresenta a metodologia utilizada na realização dos experimentos e os resultados obtidos; Por fim, na Seção 6 são apresentadas algumas conclusões e trabalhos futuros.

\section{REVISÃO BIBLIOGRÁFICA}

Uma imagem digital pode ser definida como uma função de duas dimensões. $f(x, y)$, onde $x$ e $y$ são as coordenadas em um plano espacial, e $f$ é a amplitude ou intensidade do nível de cinza na posição $(x, y)$ da imagem (GONZALES; WOODS 1999). De fato, esta definição clássica, repetida em vários trabalhos, trata de uma imagem em tons de cinza, pois uma imagem colorida, precisa de três componentes para definir as cores dos seus pontos, chamados de pixels (GONZALES; WOODS, 1999), ou seja, seria preciso definir $f(x, y), g(x, y)$ e $h(x, y)$.

\subsection{Modelos de Cores Padrões}

As cores são descritas usando algum modelo de cor padrão e, entre os mais conhecidos estão o RGB, HSV, YCbCr, YIQ e CMYK.

O modelo RGB utiliza como suas componentes básicas, as três cores vermelho, verde e azul, formando um espaço tridimensional definido por um cubo, com eixos $R, G$ e $B$, com valores entre 0 e 1 , conforme mostra a Figura 1. Este modelo é bastante na construção de telas de diversos equipamentos (computadores, TVs, smartfones, etc.) que operam com emissores de luz nestas três cores (RGB) (GONZALES; WOODS, 1999). 
Figura 1. Modelo de cores RGB [Gonzales e Woods 1999].

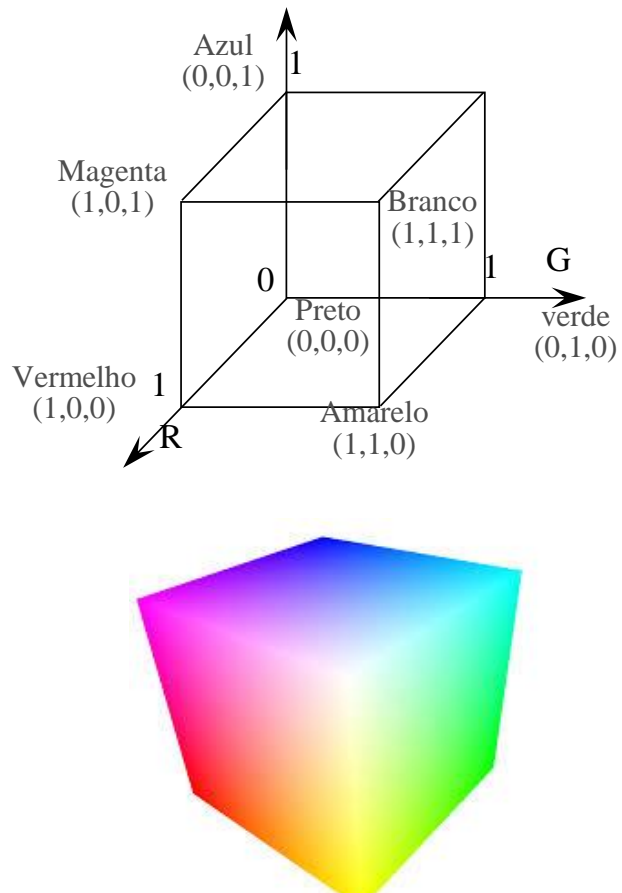

Fonte: (GONZALES; WOODS, 1999)

O modelo HSV opera de modo a separar a componente de intensidade (Value) da informação de cor e utilizar as componentes de matiz (Hue) e saturação (Saturation) relacionados à percepção humana, deste modo, sendo mais indicado para ser manipulado pelas pessoas (GONZALES; WOODS, 1999). A Tonalidade ou Matiz corresponde à medida do comprimento de onda médio da luz que reflete ou emite um objeto, isto define a cor, atingindo valores entre $0^{\circ}$ e $360^{\circ}$ mas, para algumas aplicações, esse valor é normalizado entre 0 e 100\%. A Saturação é a "pureza" da cor, quanto menor esse valor, mais com tom de cinza aparecerá a imagem e, quanto maior o valor, mais "pura" será a imagem, ou seja, com as cores mais limpas e, sem a presença do branco, que é formado por uma mistura de cores. A Saturação expressa o intervalo de comprimentos de onda ao redor do comprimento de onda médio no qual a energia é refletida ou transmitida, atingindo valores entre 0 e $100 \%$. O Valor ou Brilho define o brilho da cor, atingindo valores entre 0 e 100\%.A Figura 2 apresenta o sólido de cor do sistema HSV (Gomes e Velho, 1994]. O modelo HSI, com as componentes Matiz (H), Saturação (S) e Intensidade (I) tem uma construção parecida com o modelo HSV.

Figura 2. Sólido de cor do sistema HSV
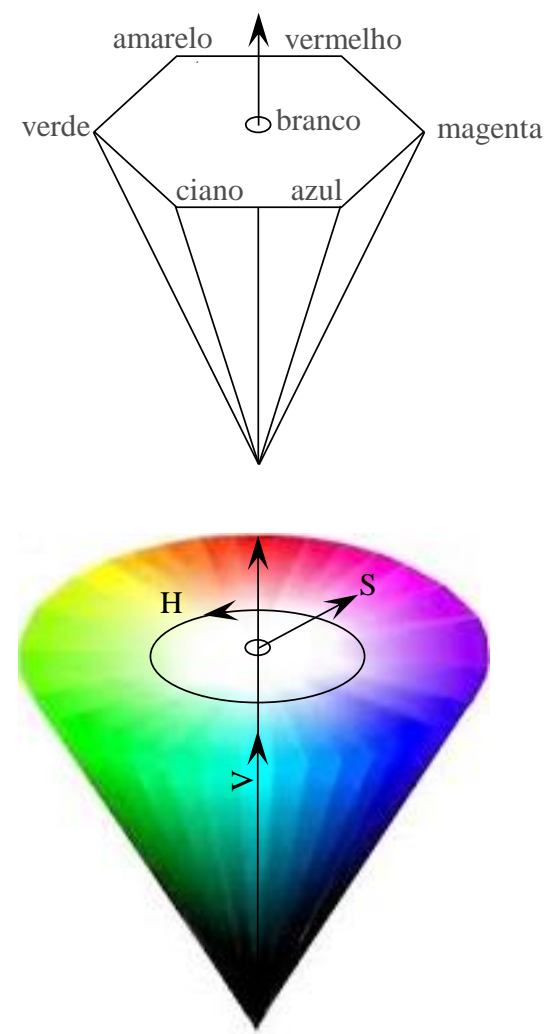

Fonte: (GOMES; VELHO, 1994).

O modelo YIQ foi proposto para permitir a transmissão da informação de intensidade $Y$ (nível de cinza) para as TVs em preto e preto, que utilizam apenas esta informação para gerar suas imagens e, para as TVs coloridas, além de $Y$, também é enviada a informação de cor l e Q (GONZALES; WOODS, 1999). Nas TVs coloridas, após a recepção destas três componentes (YIQ), elas são convertidas para o modelo RGB, para gerar a imagem na tela da TV, que opera com o modelo RGB.

O modelo CMYK é usado nas impressoras coloridas, que usam cartuchos com as cores ciano (C), magenta (M) e amarelo (Y). Por causa da dificuldade em se obter o preto combinando estas três componentes, posteriormente, foi adicionado um cartucho com a cor preta (K). Assim, quando uma imagem na tela vai ser impressa, cada pixel da tela deve ser 
convertido do modelo RGB para o modelo CMYK, para indicar as quantidades de tinta que cada cartucho deve injetar no papel.

O modelo $\mathrm{YCbCr}$ consiste em uma família de espaços de cores usados em sistemas de vídeo e fotografia digital. Y é a componente luma e $\mathrm{Cb}$ e $\mathrm{Cr}$ são as componentes de crominância, diferença de azul e vermelho, respectivamente. $\mathrm{YCbCr}$ não é um espaço de cor absoluto, mas sim uma forma de codificar informação RGB.

\subsection{Equalização de Imagens}

A equalização é uma operação que procura, estatisticamente, obter uma melhor distribuição dos níveis de cinza da imagem, objetivando corrigir a iluminação de uma imagem. A operação é feita usando o histograma da imagem, que consiste em uma tabela ou gráfico com as quantidades (frequências) de pixels com os diferentes níveis de cinza. A Figura 3 mostra em (a) o histograma de uma imagem com baixo contraste, ou seja, seu nível mais escuro é próximo de seu nível mais alto. Em (b) tem-se o histograma de uma imagem com alto contraste, ou seja, ela possui pixels muito escuros e muito claros.

Figura 3. a) Histograma de imagem com pouco contraste e b) Histograma de imagem com alto contraste.

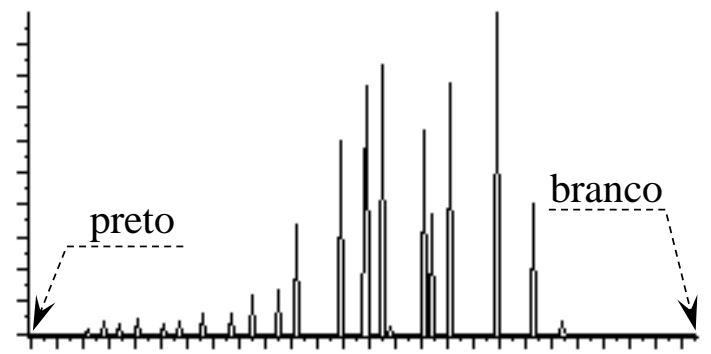

(a)

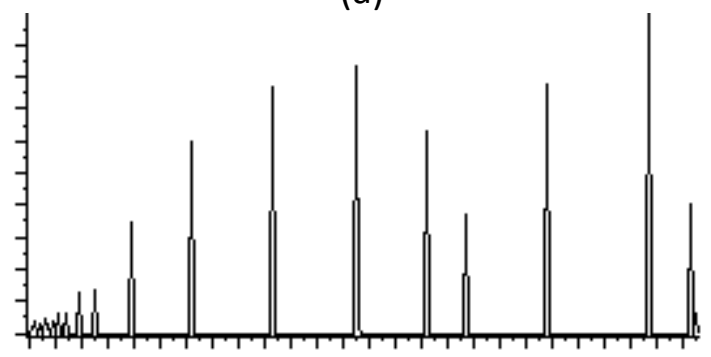

(b)
Com a equalização da imagem, ocorre uma melhora na visualização de certos detalhes. $O$ valor equalizado é obtido com a Equação 1.

$$
V e=\text { máximo }\left[0, \text { round }\left(\frac{C M . F A}{C . L}\right)-1\right]
$$

onde: Ve é o Valor Equalizado; $C M$ é o Valor máximo de cinza; $F A$ é a Frequência Acumulada (no histograma); $C$ é o número de colunas da imagem e $L$ é o número de linhas.

\subsubsection{Equalização de Imagens Coloridas}

A equalização do histograma é um processo não linear e, no caso de imagens coloridas, com três componentes, realizar a equalização de cada componente separadamente pode alterar drasticamente as cores. Assim, é comum afirmar que a equalização envolve apenas valores de intensidade da imagem, não os componentes da cor. Em geral, para uma imagem em cores RGB simples, a equalização do histograma não pode ser aplicada diretamente nas componentes, sendo indicado equalizar apenas os valores de intensidade, sem perturbar o equilíbrio de cores da imagem. Usando esta estratégia, a primeira etapa é converter o espaço de cores da imagem de RGB em um dos espaços de cores que separam os valores de intensidade dos componentes de cores. Algumas das opções possíveis são $\mathrm{HSV} / \mathrm{HLS}, \mathrm{YUV}, \mathrm{YIQ}, \mathrm{YCbCr}$, etc. $\mathrm{O}$ modelo $\mathrm{YCbCr}$ é um dos mais usados, pois foi projetado para imagens digitais. Em seguida, realiza-se a equalização do histograma no plano de intensidade $\mathrm{Y}$ e, por fim, converte-se a imagem $\mathrm{YCbCr}$ resultante, novamente em RGB.

\subsection{Detecção de Bordas}

A deteç̧ão de bordas é uma técnica que objetiva encontrar os limites dos objetos presentes nas imagens. A maneira mais usada para encontrar as bordas consiste na aplicação de máscaras de convolução (filtros), que calculam as diferenças (derivadas) entre os pixels no local calculado 
(MCANDREW 2004). Entre os filtros de detecção de bordas mais usados, merece destaque o filtro de Sobel que aplica uma suavização no local e também detecta as diferenças de intensidade (bordas). 0 método utiliza duas máscaras $3 \times 3$, para estimar os gradientes (variações de tons) na imagem, considerando as direções vertical $(G x)$ e horizontal (Gy). As máscaras utilizadas para calcular $G x$ e $G y$ são apresentadas na Figura 4.

Figura 4. Máscaras usadas por Sobel para calcular a) Gx e b) Gy.

\begin{tabular}{|l|l|l|}
\hline-1 & 0 & 1 \\
\hline-2 & 0 & 2 \\
\hline-1 & 0 & 1 \\
\hline
\end{tabular}

(a)

\begin{tabular}{|l|l|l|}
\hline-1 & -2 & -1 \\
\hline 0 & 0 & 0 \\
\hline 1 & 2 & 1 \\
\hline
\end{tabular}

(b)

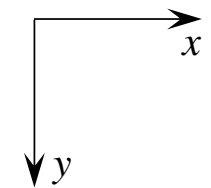

Estas máscaras são aplicadas na imagem, uma por vez, em uma operação de convolução, resultando nos gradientes calculados nas direções vertical e horizontal $G x$ e Gy, que combinados, resultam na direção $D$ da borda (Equação 2) e na magnitude $M$ da borda (Equação 3) (GONZALES; WOODS, 1999).

$$
\begin{gathered}
D=\tan ^{-1} \frac{G y}{G x} \\
M=\sqrt{G x^{2}+G y^{2}}
\end{gathered}
$$

\subsubsection{Detector de bordas Canny}

O Detector de bordas de Canny (1986) consiste em uma das melhores opções atuais para se encontrar bordas em uma imagem. Seus bons resultados decorrem do uso de um algoritmo composto por quatro etapas: 1) Aplica-se um filtro Gaussiano ( $\sigma$ definido pelo usuário) para suavizar a imagem e remover os ruídos, que geram bordas falsas; 2) Encontra-se a intensidade dos gradientes da imagem (aplicando Sobel); 3) Aplica-se a técnica de supressão não máxima para afinar as bordas (mantém apenas o pixel com o maior nível de cinza na largura da borda); 4) Aplica-se uma limiarização dupla (histeresis) para manter os pixels de borda com nível de cinza acima do limiar superior $(L s)$, eliminar os pixels de borda com nível de cinza abaixo do limiar inferior $(L i)$ e, analisar os pixels com nível de cinza entre $L i$ e $L s$, mantendo aqueles que possuem vizinhos acima de $L s$ (para evitar quebras nas linhas de borda). Deste modo, enquanto o filtro de Sobel simplesmente detecta as bordas, o detector de Canny consiste em um algoritmo mais elaborado, que suaviza, detecta e afina as bordas e, ainda, evita as interrupções das linhas de borda. Como permite alterar o nível de suavização $\sigma$ e os limiares $L i$ e $L s$, também permite obter diferentes respostas. A Figura 5 mostra as diferenças entre os resultados obtidos com o detector de Sobel e Canny.

Figura 5. a) Imagem original; b) Bordas detectadas com Sobel; c) Bordas obtidas com Canny.

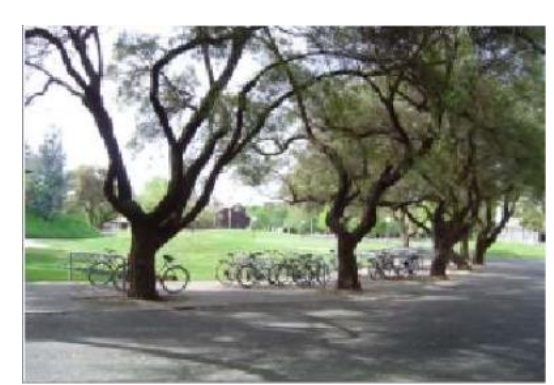

(a)

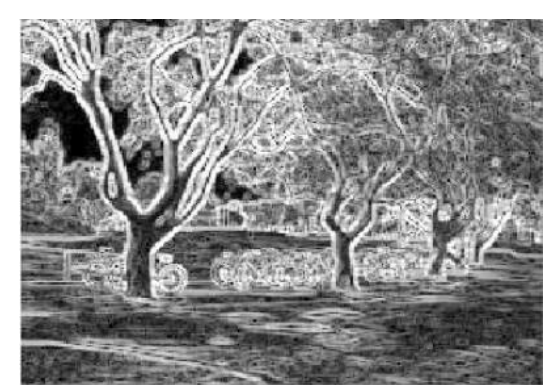

(b)

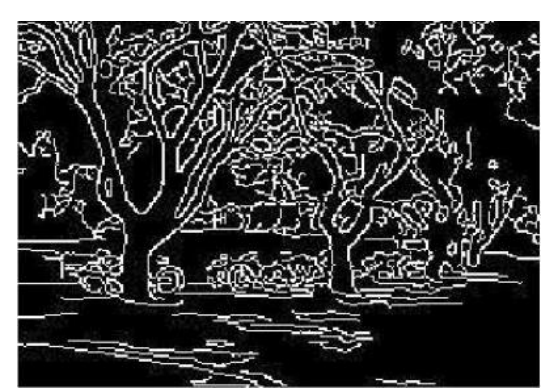

(c)

\section{TRABALHOS RELACIONADOS}

Jianwei (2013) propõe um método para realce de contraste de cor em cada componente de cor no modelo RGB. Com o realce de contraste de cor em cada componente do modelo $R G B$, os resultados mostram que esse método mantém mais detalhes de bordas nas imagens, do que o 
método convencional, no qual a imagem colorida é composta em componentes do RGB depois são detectadas as bordas em cada componente e, em seguida, a imagem colorida é recomposta. Como o método trabalha com as componentes do RGB não é necessário transformar um modelo de cores em outro, isso torna o método bem simples. Na Figura 6 é mostrado um dos resultados do trabalho de Jianwei (2013). Na Figura 6(a) tem-se a imagem original; na Figura 6(b) temse a imagem que passou pelo o realce de contraste de cor em cada componente RGB, proposto por Jianwei (2013); na Figura 6(c) tem-se o resultado da deteç̧ão de borda da imagem da Figura 6(a) utilizando Prewitt (operador para detectar bordas em imagens).

Figura 6. Resultado da detecção de bordas em imagens coloridas proposto por Jianwei [2013].

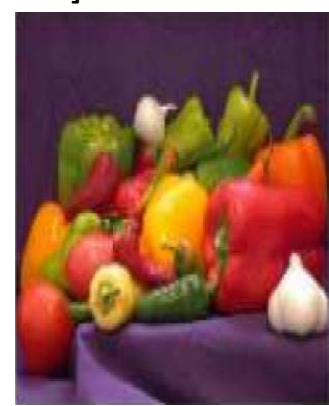

(a)

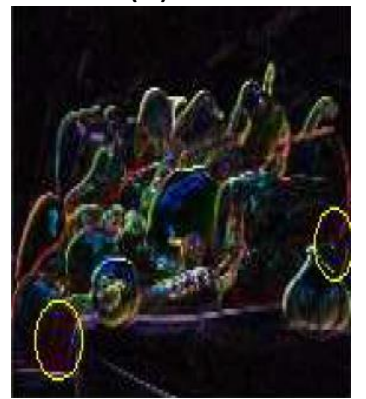

(c)

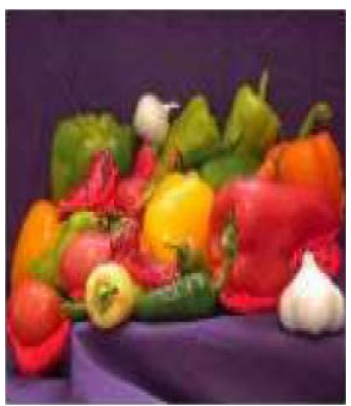

(b)

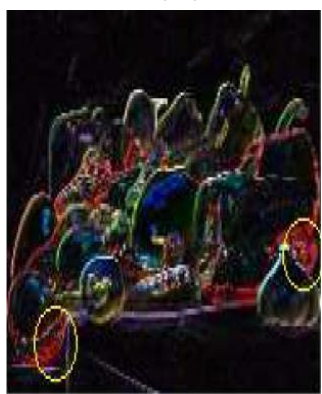

(d)
Fonte: Jianwei (2013)

Na Figura 6(d) tem-se o resultado da detecção de borda da imagem da Figura 6(b) utilizando Prewitt. Os círculos destacados em amarelo na Figura 6(c) e Figura 6(d), destacam que em (d) foram detectadas bordas que não foram detectadas em (c). Com isso o método proposto por Jianwei (2013), mantém mais detalhes de bordas nas imagens, do que o método convencional de detecção de bordas.

No trabalho de Xu et al. (2012) é utilizado um método para quantificar informações de cor e também detectar bordas em imagens coloridas. O método utiliza o volume de um pixel no espaço de cor HSI, junto com a redução de ruído, thresholding e afinamento de borda. Os resultados mostraram um melhoramento na precisão das detecções das bordas nas imagens mesmo quando há bastante ruído nelas. Na Figura 7 é apresentado um dos resultados do trabalho de $\mathrm{Xu}$ et al. (2012). Em (a) tem-se a imagem original; Em (b) temse o resultado da detecção de bordas da imagem original com o método proposto por Xu et al. (2012); Em (c) tem-se o resultado da detecção de bordas da imagem original utilizando Canny; Em (d) tem-se o resultado da deteç̧ão de bordas da imagem original utilizando Prewitt. As elipses em vermelho na Figura 7(b) e Figura 7(c) destacam que em (c) uma das antenas da borboleta ficou falhada, o que não aconteceu em (b). Já as elipses destacadas em vermelho na Figura 7 (b) e 7(d), mostram que em 7(d) não é encontrada uma borda entre o fundo e a folha em que a borboleta está em cima, já em 7(b) essa borda é encontrada. O método proposto por $\mathrm{Xu}$ et al. (2012), neste caso, apresentou um melhor resultado com relação à Canny e Prewitt, para se detectar bordas em uma imagem colorida.

Figura 7. Resultados de diferentes detectores de bordas em uma imagem colorida (XU et al., 2012).

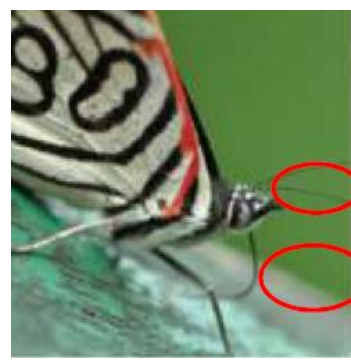

(a)

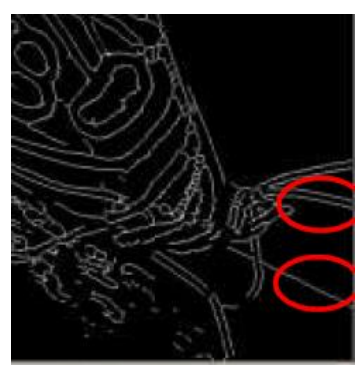

(b) 


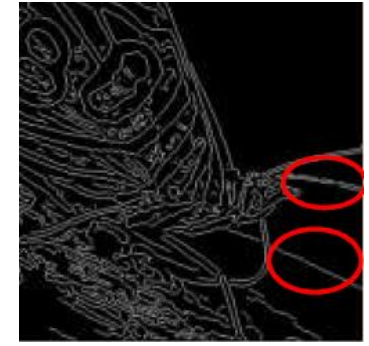

(c)

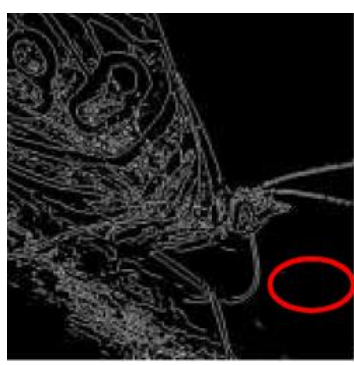

(d)
No trabalho de Gonzaga e Boaventura (2009) é feita uma avaliação do desempenho de detectores de bordas, os detectores de bordas avaliados são Canny, Sobel e Russo. São utilizadas imagens sintéticas e imagens de cenas reais, para se fazer uma avaliação quantitativa. A avaliação quantitativa consiste nas seguintes medidas: semelhança entre dois contornos, número de pixels de borda detectados corretamente, número de pixels de bordas que foram erroneamente detectados como pixels de borda, número de pixels de bordas não detectados, porcentagem de pixels corretamente detectados (Pco), a porcentagem de pixels não detectados (Pnd), a porcentagem de pixels classificados erroneamente como pixels de borda (Pfa) e índice global. Os resultados das medidas dos detectores de bordas avaliados são mostrados em uma tabela. Este trabalho diferencia-se dos demais por fazer detecção de bordas em imagens coloridas, utilizando vários canais de vários sistemas de cores, e também misturando eles, para se detectar a borda. 0 desempenho dos detectores de bordas adaptados, foram comparados com o desempenho dos métodos convencionais de detecção de bordas usando OpenCV. O trabalho também fez experimentos com equalizações de imagens utilizando canais de diferentes sistemas de cores.

\section{METODOLOGIA}

Neste trabalho são utilizadas imagens coloridas bastante divulgadas na literatura e imagens sintéticas, criadas especialmente para avaliar as técnicas propostas. As imagens avaliadas são processadas com a estratégia convencional, usando o OpenCV, ou seja, a imagem é convertida para tons de cinza e, em seguida, o detector de bordas é aplicado. Com a proposta apresentada neste trabalho, aplica-se o detector de bordas usando as componentes de cores, usando diferentes modelos de cores e, em seguida, os resultados são combinados de diferentes maneiras. As análises das detecções são feitas qualitativamente, comparando-se, visualmente, as bordas encontradas pelas diferentes estratégias e, também, quantitativamente, calculando os pixels de bordas encontrados pelas diferentes abordagens. Neste trabalho são usados os cinco modelos de cores: RGB, YIQ, HSV, CMYK, YCbCr.

\subsection{Equalização de Imagens Coloridas}

A equalização da imagem precisa ser realizada apenas na informação de brilho (nível de cinza) da imagem, assim, pode ser facilmente aplicada usando os modelos HSI, HSV e YIQ, que separam a informação de brilho das informações de cores, assim, o procedimento consiste em equalizar os valores de brilho e, em seguida, juntar as informações de cor, para se obter a imagem colorida equalizada.

\subsubsection{Equalização usando a componente} correspondente ao nível de cinza (tradicional)

Esta estratégia toma imagens coloridas, usando o modelo RGB, obtém as componentes usando os sistemas de cor que possuem a separação da informação de brilho da informação de cor, como o HSV, YIQ e $\mathrm{YCbCr}$. Após equalizar o canal com a informação de brilho, converte de volta para o sistema de cor RGB, para obter a imagem.

\subsubsection{Proposta de equalização diretamente no modelo $R G B$}

Esta proposta sugere processar a equalização de imagens coloridas usando o seguinte algoritmo:

1) Encontrar o nível de cinza de cada pixel calculando $Y=0,299 . R+0,587 . G+0,114 . B$; 
2) Realizar a equalização dos níveis de cinza (usando o histograma de níveis de cinza);

3) Para cada pixel, obter um fator $f_{\text {equ }}$, dado

$$
\text { por } f_{\text {equ }}=\frac{\text { nível de cinza original }}{\text { nível de cinza equalizado }}
$$

4) Calcular $\max R G B=\operatorname{máximo}\{R, G, B\}$;

5) Se $\left(\max R G B . f_{\text {equ }}\right)>255$, calcular

$$
f_{\text {equ }}=\frac{255}{\max R B} ;
$$

6) Multiplicar os valores de R, G e B por $f_{\text {equ }}$

Este algoritmo evita a necessidade de se converter de RGB para outros modelos, como o HSV, YIQ ou $\mathrm{YCbCr}$ e, realiza o aumento do brilho alterando as três componentes de cor (RGB) com o mesmo valor, para alterar apenas a tonalidade e não a cor final .

\subsection{Detecção de bordas usando informação de cor}

Esta estratégia toma imagens coloridas, usando o modelo RGB, obtém as componentes de cor usando os sistemas de cor YIQ, HSV, CMYK, YCbCr. Em seguida, aplica os detectores de borda (Sobel ou Canny) em todas as componentes de cor e, por fim, utiliza uma forma de combinar os resultados do detector de bordas para cada componente para compor a imagem final. 0 algoritmo usado consiste nos quatro passos:

1) A imagem colorida é decomposta em canais dos sistemas de cores mencionados. Canais: R, G, B, Y, I, Q, H, S, V, C, M, Y, Y, Cb, $\mathrm{Cr}$;

2) Escolha dos canais e da técnica de composição da imagem;

3) Detecção de bordas nos canais escolhidos utilizando Sobel;

4) Composição da imagem de acordo com a técnica escolhida no passo 2 .

Considerando os canais $\mathrm{Ci}$ dos sistemas de cores escolhidos, os métodos propostos para fazer a composição da imagem final foram: a) Magnitude: $A$ cor do pixel no sistema RGB é obtida fazendo $R=$ mag, $G=$ mag e $B=$ mag;

b) Máximo - A cor do pixel no sistema RGB é obtida fazendo $R=$ máx, $G$ = máx e $B=$ Max (imagem de bordas em tons de cinza);

c) Mínimo - A cor do pixel no sistema RGB é obtida fazendo $R=$ mín, $G=$ mín e $B=$ mín (imagem de bordas em tons de cinza);

d) Média - A cor do pixel no sistema RGB é obtida fazendo $R=$ med, $G=$ med e $B=$ med (imagem de bordas em tons de cinza);

e) Or - A cor do pixel no sistema RGB é obtida fazendo $\mathrm{R}=$ or, $\mathrm{G}=$ or $\mathrm{e} B=$ or (imagem de bordas em tons de cinza);

f) And - A cor do pixel no sistema RGB é obtida fazendo $R=$ and,$G=$ and $e ~ B=$ and (imagem de bordas em tons de cinza);

g) Xor - A cor do pixel no sistema RGB é obtida fazendo $R=$ xor, $G=$ xor e $B=x o r$ (imagem de bordas em tons de cinza);

\subsubsection{Avaliação dos detectores de borda}

São apresentadas análises quantitativas e qualitativas dos detectores de bordas, adaptados aqui nesse trabalho e dos detectores de bordas padrões. Para se fazer as análises qualitativas, foram detectadas bordas nas imagens coloridas com os detectores de bordas adaptados e também com detectores de bordas padrões. As bordas encontradas com os detectores de bordas adaptados, que não foram encontradas pelos os detectores de bordas padrão, foram destacadas de vermelho em uma imagem resultado. Para as análises quantitativas, são usadas imagens sintéticas, pois nestas imagens, as quantidades de pixels de bordas são previamente conhecidas. Deste modo, a análise consistiu em contar o número de pixels de bordas encontradas pelos os detectores de bordas adaptados e os detectores de bordas padrão. 


\section{RESULTADOS}

Nesta seção são apresentados os resultados mais relevantes no uso de diferentes combinações de componentes.

\subsection{Equalização de Imagens}

Quando a equalização é aplicada nas componentes com informações de cor, obtém-se uma alteração das cores, que pode comprometer o conteúdo da imagem, no caso da imagem ser analisada visualmente (por pessoas). Por outro lado, no caso de sistemas de análise automática, esta possibilidade pode ser usada em situações específicas. A Figura 8 mostra um exemplo de equalização de imagem colorida. Em (a) temse a imagem original e, em (b), o resultado da equalização dos três canais RGB, que as componentes com informações de cores e, assim, a imagem fica comprometida, pelo fato das cores serem muito diferentes das cores da imagem original, não representando mais o mesmo objeto na imagem. Em (c) tem-se o resultado da equalização componente $\mathrm{Y}$ do modelo de cores $\mathrm{YCbCr}$, também com um resultado satisfatório. Em (d) tem-se o resultado da equalização usando as três componentes RGB, usando o algoritmo proposto, onde se observa uma preservação das cores, tal como ocorre em (c), que faz a conversão para o modelo YCbCr. Entretanto, em (c), as imagens ficam com cores mais apagadas, enquanto que (d), as cores ficam mais vivas.

Figura 8. a) Imagem original; b) Equalização das componentes $R, G$ e B; c) Equalização da componente $\mathrm{Y}(\mathrm{YCbCr})$.; d) Equalização das componentes $\mathrm{R}, \mathrm{G}$ e B usando o algoritmo proposto.

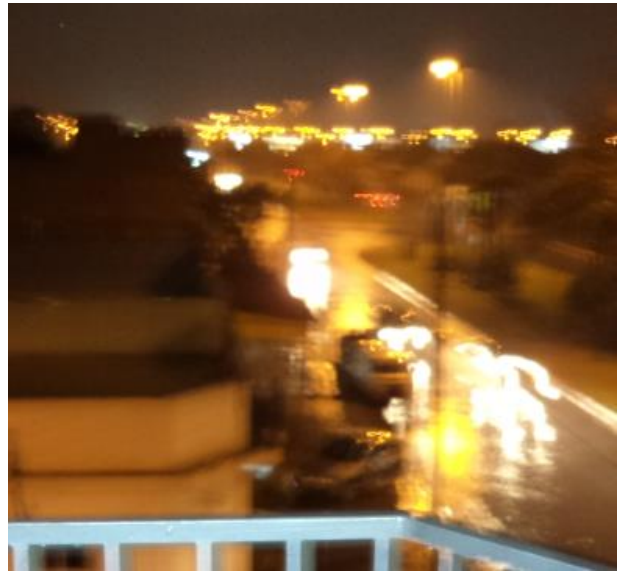

(a)

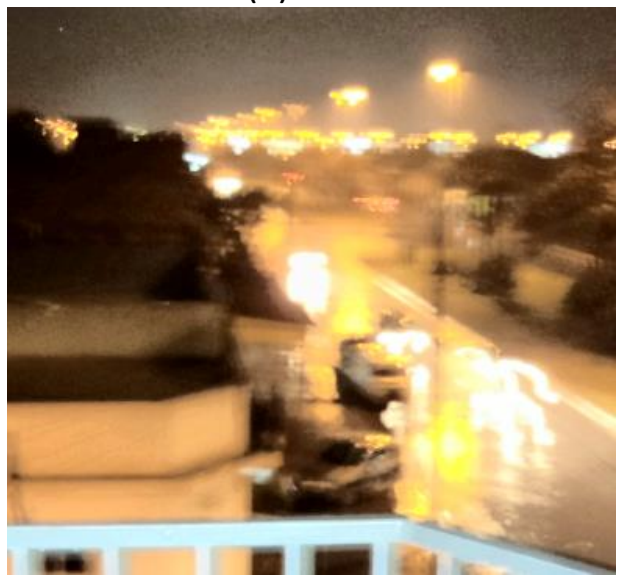

(c)

De fato, para a equalização de imagens coloridas serem analisadas visualmente, o procedimento usual consiste em usar modelos de cores, que possuam um

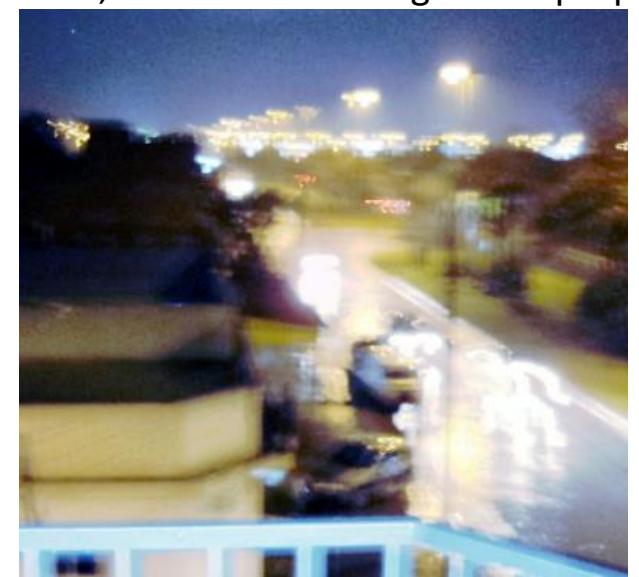

(b)

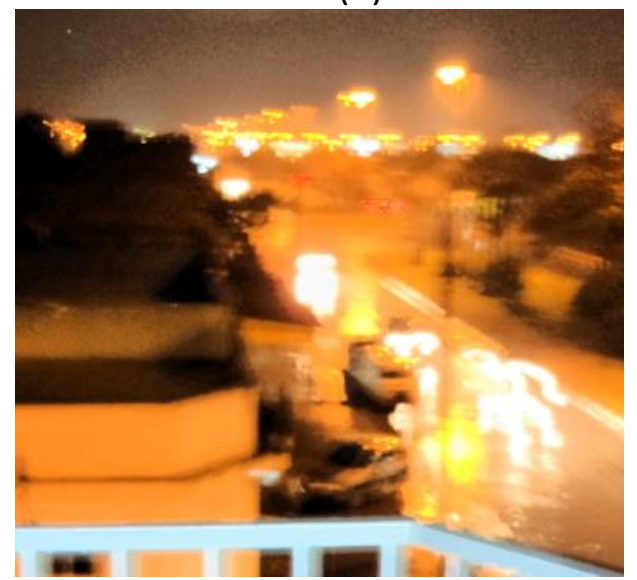

(d)

componente com a informação de brilho separado das componentes de cores.

A Figura 9 apresenta em (a), uma imagem original, que possui uma distribuição 
de iluminação muito ruim, tornando difícil visualizar a face da pessoa fotografada. Em (b) tem-se o resultado da equalização das três componentes de cores RGB, onde se verifica que a cor verde da mata ao fundo foi muito modificada. Em (c) tem-se o resultado da equalização usando modelo $\mathrm{YCbCr}$, onde se obtém a melhora da iluminação da imagem, com um boa preservação das cores da imagem original. Por fim, tem-se em (d) o resultado da equalização usando o modelo $R G B$, usando o algoritmo proposto e, assim, observa a preservação da cor verde da vegetação ao fundo e, também uma cor de pele mais natural.

Figura 9. a) Imagem original e seu histograma; b) Equalização usando as componentes RGB; c) Equalização usando a componente $\mathrm{Y}(\mathrm{YCbCr})$; d) Equalização usando as componentes RGB com o algoritmo proposto.

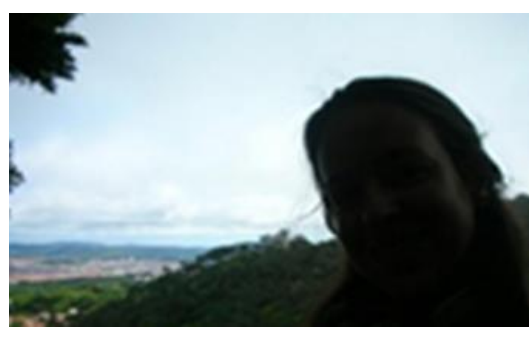

(a)

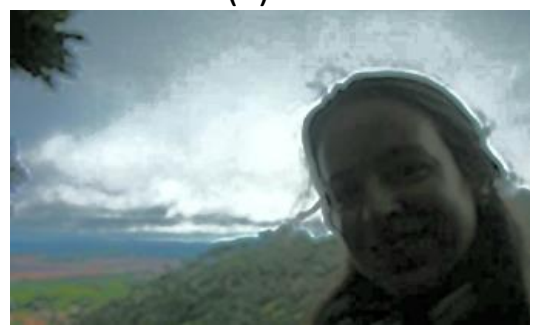

(c)

A Figura 10 (b) apresenta $O$ resultado obtido com a equalização convertendo RGB para YCbCr. Em (c) tem-se o resultado obtido usando o algoritmo proposto neste trabalho, que aplica a equalização diretamente nas componentes RGB, dispensando a necessidade de conversões entre os modelos de cor ( $\mathrm{RGB} \rightarrow \mathrm{YCbCr}$ e $\mathrm{YCbCr} \rightarrow \mathrm{RGB})$. Nesta figura é possível observar, visualmente $e$

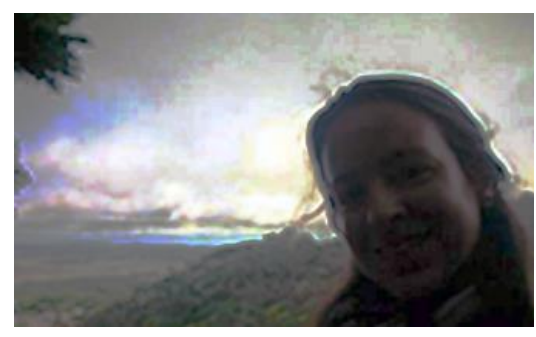

(b)

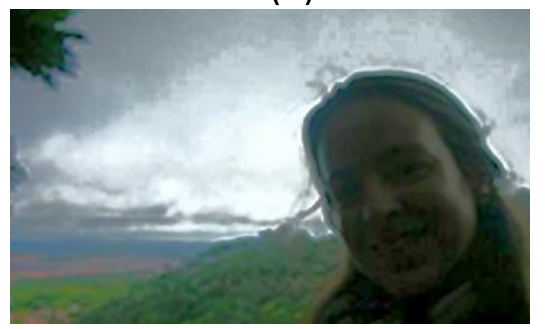

(d)

através de seus respectivos histogramas, a melhor distribuição nos níveis das imagens em (b) e (c). Também se verifica a preservação das cores (cinza e azul) usando o método tradicional, que faz a conversão para o modelo $\mathrm{YCbCr}$ e a proposta apresentada neste trabalho, que realiza a equalização diretamente no modelo RGB. 
Figura 10. a) Imagem original e seu histograma; b) Resultado obtido com a equalização usando o modelo $\mathrm{YCbCr}$ e seu histograma; c) Resultado obtido (e seu histograma) usando a equalização usando o algoritmo proposto.

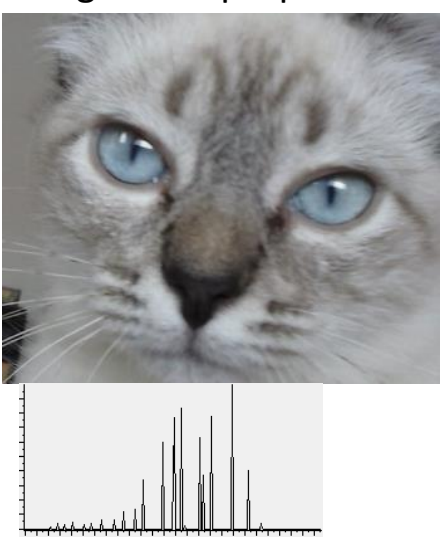

(a)

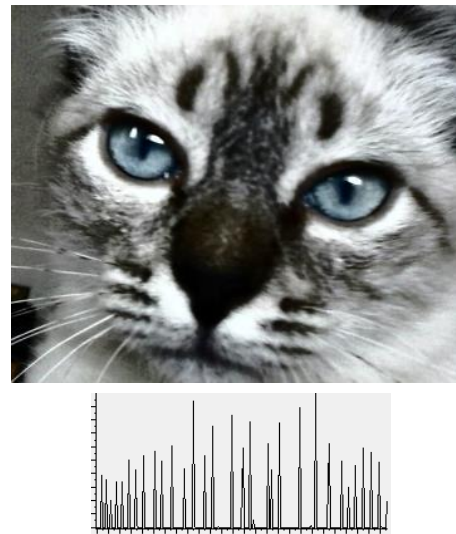

(b)

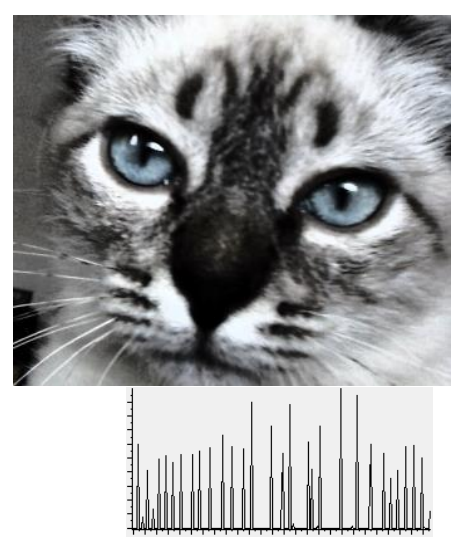

(c)
A Figura 11 mostra um exemplo com uma gama maior de cores, em que também é possível observar o maior contraste em (b) e (c), ainda, uma adequada preservação das cores da imagem original em (a)

Figura 11. a) Imagem original; b) Resultado obtido com a equalização usando o modelo YCbCr; c) Resultado obtido usando a equalização usando o algoritmo proposto.

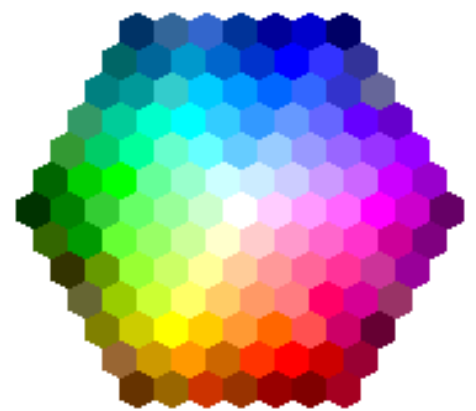

(a)

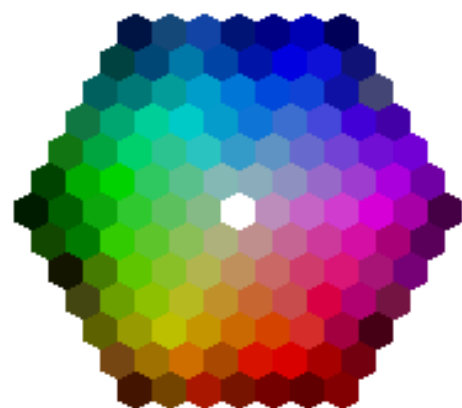

(b)

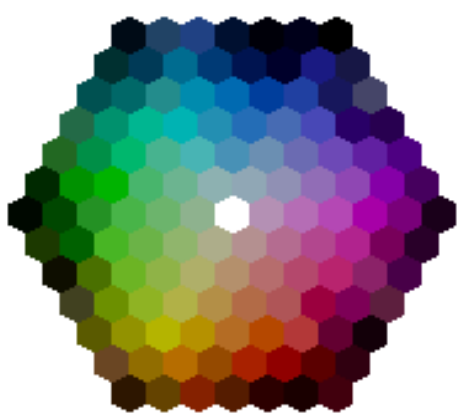

(c)

\subsection{Detecção de Bordas}

$\mathrm{Na}$ deteç̧ão de bordas de imagens coloridas as componentes com informações de cores podem ser usadas, precisando apenas definir a melhor maneira de compor a imagem final, combinando os resultados dos detectores nas diferentes componentes de cores. Este trabalho aponta que os melhores resultados são obtidos utilizando os operadores máximo e or. Os operadores média e magnitude apresentam resultados medianos, enquanto que os operadores and e xor apresentam resultados muito ruins. $\mathrm{Na}$ Figura 12 são mostrados os resultados dos detectores de bordas adaptados (usando diversas componentes de cores) e o detector de borda padrão Sobel implementado com OpenCV;

Em (a) tem-se a imagem original e, em (b), a imagem com a aplicação de Sobel em todos os 15 componentes dos modelos de cores, combinados com o operador xor. Em (c), tem-se a imagem com a aplicação de Sobel em 13 componentes dos modelos de cores (excluídos as componentes $\mathrm{H}$ e V), combinados com o operador or. Em (d), temse a imagem com a aplicação de Sobel nas componentes $\mathrm{R}, \mathrm{G}$ e $\mathrm{B}$, combinados com o operador máximo. Em (e), tem-se a imagem convertida para tom de cinza e depois aplicado Sobel com OpenCV. Nota-se que em (b) o resultado não ficou bom, pois as bordas ficaram muito sinuosas. Já em (c) e (d) os 
resultados da deteç̧ão de bordas ficaram semelhante ao resultado do Sobel do OpenCV. Observando no interior dos círculos destacados em azul, nota-se que o melhor dos resultados é (c). Em (c) nota-se que quase praticamente foram só detectadas as bordas da imagem original. Em (e), vendo o interior do círculo azul nota-se que há detalhes a mais na imagem além das bordas. Nesta imagem, é difícil perceber todas as diferenças de resultados, por causa de uma grande variedade de cores nas bordas.
Entretanto, deve-se levar em consideração que nos processamentos tradicionais, quando a imagem é convertida para tons de cinzas, há perda de informações e, consequentemente, de bordas. A implementação tradicional com o OpenCV utiliza a Equação 4 para transformar uma imagem colorida (RGB) em tons de cinza.

$$
Y=0,299 . R+0,587 . G+0,114 . B
$$

onde: $R, G, B$ são as componentes de cor do modelo RGB e Y é o tom de cinza resultante.

Figura 12. Aplicação do detector de bordas Sobel a) Imagem original; b) Aplicação de Sobel nas componentes de cores R, G, B, Y, I, Q, H, S, V, C, M, Y, Y, Cb, Cr combinadas com o operador xor; c) Aplicação de Sobel em 13 componentes dos modelos de cores (excluídos $\mathrm{H}$ e V), combinadas com o operador or d) Aplicação de Sobel nas componentes R, G e B, combinadas com o operador máximo e) Resultado obtido com a aplicação de Sobel na imagem em tons de cinza.

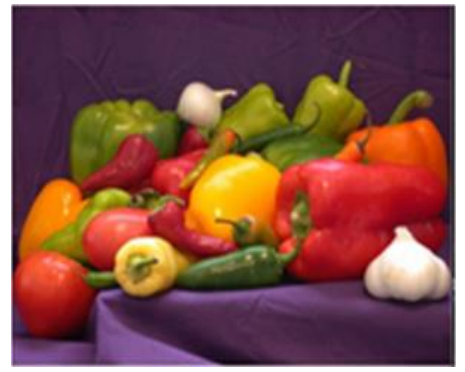

(a)

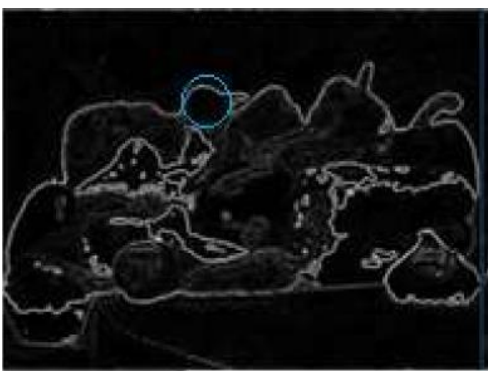

(b)

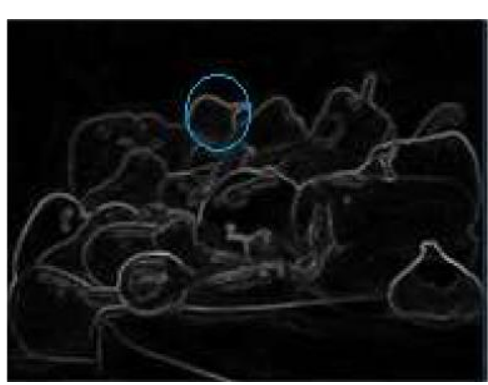

(c)

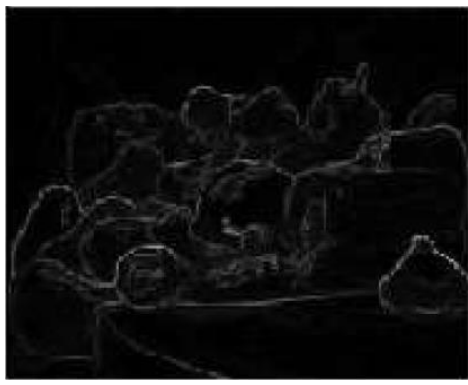

(d)

O problema que se observa aqui é que usando a Equação 4, para converter uma imagem em tom de cinza, pixels com cores diferentes podem receber o mesmo valor de tom de cinza e, assim, não é possível fazer uma detecção da borda entre estes pixels. A Figura 13 ilustra este caso, pois a imagem possui uma região triangular verde e uma região retangular magenta, que tem 0 mesmo valor de tom de cinza, quando calculado usando a Equação 4. Além disso, nesta imagem simples é possível fazer uma análise quantitativa dos resultados, pois

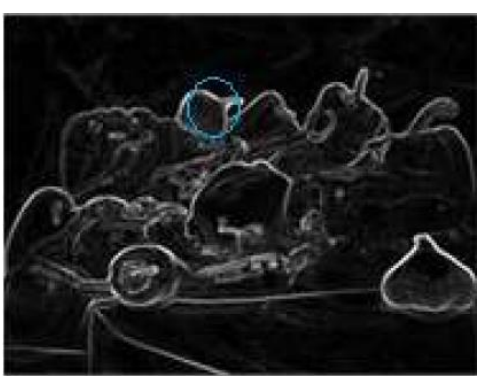

(e)

neste caso, sabe-se antecipadamente a quantidade de pixels de borda que existem na imagem. Em (a) tem-se a imagem original, com 1.927 pixels de borda. Em (b) tem-se o Resultado da aplicação do detector de bordas (Canny) sobre as componentes de cor R, G e $B$, combinadas com o operador or. Neste caso, são detectados exatamente 1.927 pixels de borda. 
Figura 13. Detecção de bordas em uma imagem colorida: a) Imagem original; b) Resultado da aplicação do detector de bordas (Sobel) sobre as componentes de cor R, G e $B$, combinadas com o operador or; c) Resultado da aplicação do detector de bordas (Sobel) sobre a imagem convertida para tons de cinza.

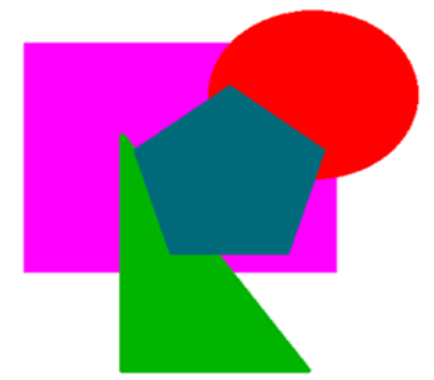

(a)

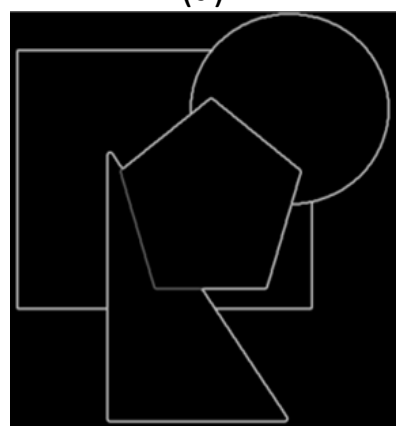

(b)

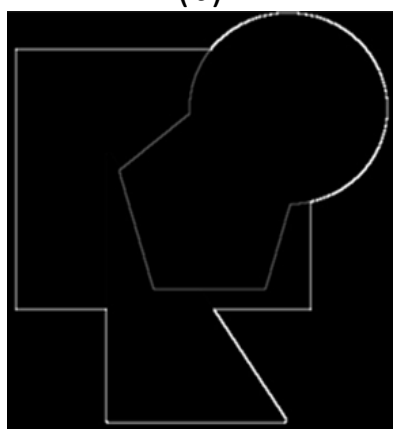

(c)

Em (c) tem-se o procedimento tradicional, usando a conversão para tons de cinza e, o uso do detector de bordas de Canny nesta imagem. Neste caso, são detectados 1.667 pixels de borda. Em (b) e (c) são usados os mesmos valores de limiares para o Canny.

A Figura 14 apresenta outro resultado, desta vez usando o modelo de cores HSV.
Figura 14. Detecção de bordas em uma imagem colorida: a) Imagem original; b) resultado da aplicação do detector de bordas de Canny nas componentes $\mathrm{H}, \mathrm{S}$ e $\mathrm{V}$, combinadas usando o operador or; c) Resultado obtido com a aplicação do detector de Canny sobre a imagem em tons de cinza.

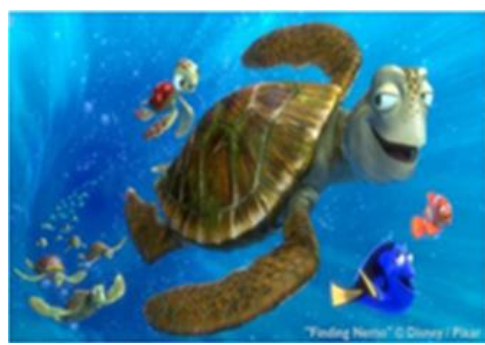

(a)

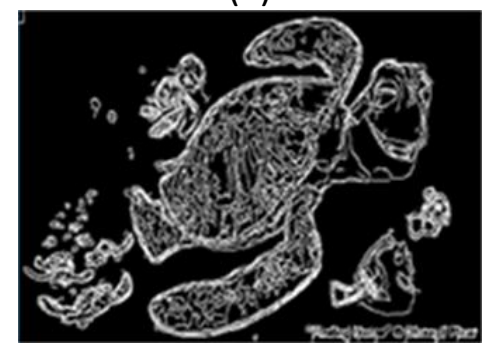

(b)

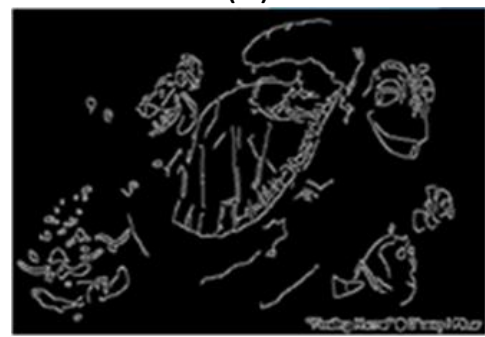

(c)

Em (a) tem-se a imagem original. Em (b) tem-se o resultado da aplicação do detector de bordas de Canny (limiar inferior = 50 e limiar superior $=152$ ) nas componentes $\mathrm{H}, \mathrm{S}$ e $\mathrm{V}$ e, o resultado é obtido com o operador or. Em (c) tem-se o resultado obtido após converter a imagem para tons de cinza e aplicar o operador de Canny (mesmos parâmetros anteriores).

Por meio de análises qualitativas é possível verificar visualmente o desempenho dos detectores de bordas adaptados com relação aos detectores padrões. Na Figura 15, em (a) tem-se a imagem original; em (b) temse o resultado da aplicação do detector de bordas Canny nas componentes R, G, B, e depois combinados com o operador or; em (c) tem-se o resultado da aplicação do 
detector de bordas Canny de maneira convencional (a imagem é convertida para cinza e depois é aplicado o Canny); em (d) são destacadas em vermelho as bordas que foram encontradas em (b) e que não foram encontradas em (c).

Figura 15. Análise qualitativa do desempenho de um detector de bordas adaptado com relação à um padrão.

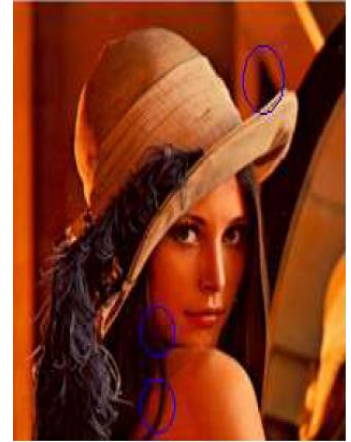

(a)

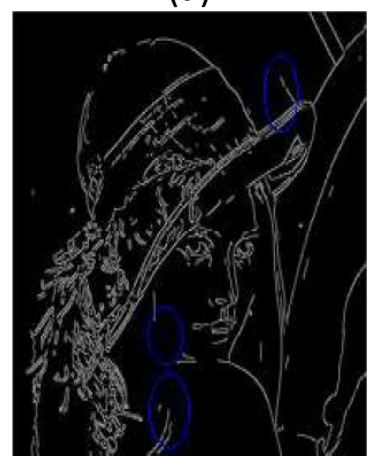

(c)

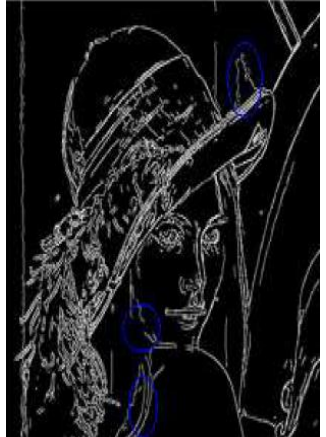

(b)

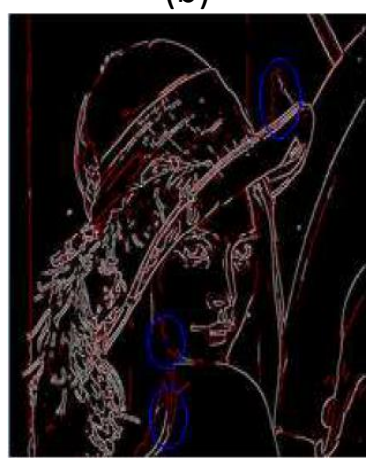

(d)
Os valores de limiar de Canny utilizados são os mesmos em (b) e (c). Observando o interior dos círculos em azul da Figura 15, nota-se que com o detector de bordas adaptado foram encontradas bordas que não foram encontradas com o detector de bordas convencional (bordas no cabelo, rosto, acima da aba do chapéu). Portanto, fazendo essa análise, note-se que o detector de borda adaptado apresentou um melhor desempenho, visual, que o detector de borda convencional.
As análises visuais são bastante eficazes para analisar a preservação das cores em um processo de equalização, entretanto, elas apresentam como desvantagem a incapacidade humana de se perceber pequenos detalhes, como a perda de bordas. Assim, para se fazer uma medição mais precisa, no resultado de um detector de bordas, o mais recomendável é usar imagens sintéticas, cujos pixels de bordas são conhecidos previamente. A Figura 16 apresenta um exemplo bastante simples de imagem desta natureza. Em (a) tem-se a imagem original; em (b) tem-se o resultado da detecção de bordas de (a) utilizando o operador de Sobel nas componentes $\mathrm{Y}, \mathrm{Cb}$ e $\mathrm{Cr}$ e, em seguida, os resultados são combinados com o operador média; em (c) tem-se o resultado da detecção de bordas de (a), utilizando Canny (OpenCV), de modo convencional (Canny aplicado sobre a imagem em tons de cinza); em (d) tem-se o resultado da detecção de bordas de (a) utilizando Canny em todos as componentes de todos os modelos de cores utilizados aqui neste trabalho, e depois os resultados foram combinados com o operador or; em (e) temse o resultado da detecção de bordas usando Sobel (OpenCV) de maneira convencional (a imagem foi convertida para tons de cinza primeiro para depois aplicar Sobel). Olhando para (c) e (e) nota-se que com o detector de borda convencional, não foi possível detectar a borda do quadrado vermelho da imagem original, borda destacada nas Figuras $16(\mathrm{~b})$ e 16(d), porque quando a imagem foi convertida para tons de cinza, antes de aplicar o detector de borda, os dois quadrados ficaram com a mesma tonalidade de cinza e, com isso, a divisão entre eles desapareceu não sendo possível detectar a borda. 
Figura 16. a) Imagem original; b) Detecção de bordas usando Sobel nas componentes $\mathrm{Y}, \mathrm{Cb}$ e $\mathrm{Cr}$, combinados com o operador média; c) Detecção de bordas usando Canny (OpenCV) aplicado sobre a imagem em tons de cinza; d) Detecção de bordas usando Canny em todos as componentes de todos os modelos de cores, combinados com OR; e) Detecção de bordas usando Sobel (OpenCV) aplicado sobre a imagem em tons de cinza.

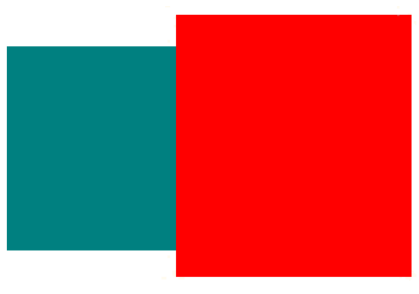

(a)

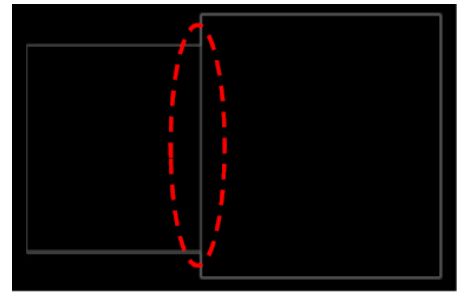

(b)

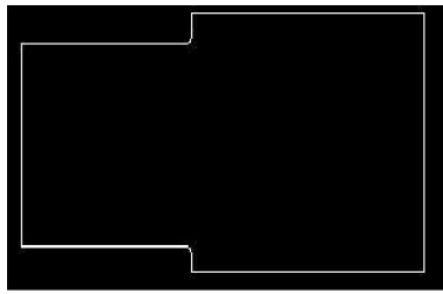

(c)

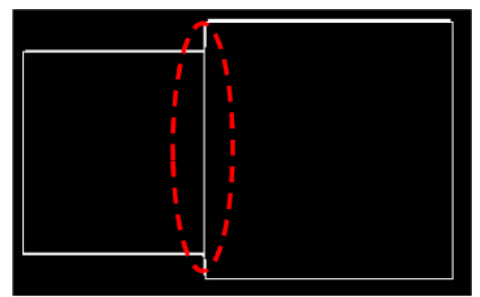

(d)

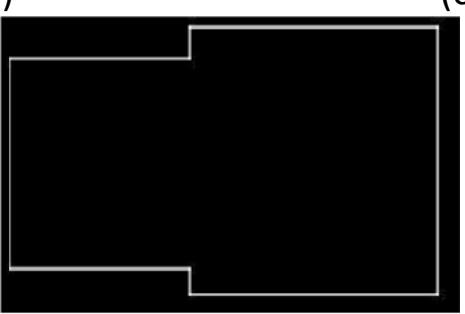

(e)
Sabendo que a quantidade de pixels de bordas da imagem da Figura 16(a) é de 1.590 pixels de borda, é possível avaliar de forma quantitativa, o resultado da extração de bordas usando estas diferentes abordagens, conforme mostra a Tabela 1.

Tabela 1. Análise quantitativa dos desempenhos dos detectores de bordas adaptados e padrão.

\begin{tabular}{l|c|c|c|c|c|c}
\hline Canais & $\begin{array}{c}\text { Método de } \\
\text { combinação }\end{array}$ & $\begin{array}{c}\text { Limiar } \\
\text { Inferior }\end{array}$ & $\begin{array}{c}\text { Limiar } \\
\text { Superior }\end{array}$ & $\begin{array}{c}\text { Detector } \\
\text { de } \\
\text { Borda }\end{array}$ & $\begin{array}{c}\text { Pixels de borda } \\
\text { detectados }\end{array}$ & $\begin{array}{c}\text { Figura } \\
16\end{array}$ \\
\hline YCbCr & Média & - & - & Sobel & $1.572(98.9 \%)$ & (b) \\
\hline Cinza & & 28 & 124 & Canny & $1.384(87,7 \%)$ & (c) \\
\hline $\begin{array}{l}\text { Todos os } \\
\text { canais }\end{array}$ & Or & 28 & 124 & Canny & $1.590(100 \%)$ & (d) \\
\hline Cinza & & - & - & Sobel & $1.398(87,9 \%)$ & (e) \\
\hline
\end{tabular}

\section{CONCLUSÕES E TRABALHOS FUTUROS}

Este trabalho apresenta propostas para se realizar o processamento de imagens (equalização e detecção de bordas) usando informações de cores. Para a equalização é apresentado uma algoritmo que utiliza apenas o modelo RGB, dispensando a conversão para um modelo de cores que separa a informação de brilho e cores e, após realizar a equalização, precisa fazer a conversão inversa, para o RGB. No caso da detecção de bordas, apresenta algumas propostas para combinar detecções usando diferentes componentes de cores.

$\mathrm{Na}$ análise quantitativa nota-se que o detector de borda adaptado encontra mais pixels de borda que o detector padrão. Quanto a análise visual os resultados mostram que o detector de bordas adaptado encontra mais bordas que o detector padrão. Esse resultado deve-se ao fato de o algoritmo de detecção de borda adaptado detecta bordas em várias componentes dos diferentes modelos de cores utilizados aqui neste trabalho e, com isso, supera o 
problema da perda de informações quando a imagem colorida é convertida para tons de cinza para se aplicar o detector de bordas. Para fazer equalizações em imagens coloridas mostrou que não é possível separar a imagens em componentes, equalizar cada um deles, e mostrar o resultado. Para equalizar imagens coloridas deve-se separar a imagem em componentes em que tem os valores de intensidade da imagem separados das componentes de cores. Com isso, quando é feita a equalização desses componentes, as cores não ficam distorcidas e apresentam um resultado coerente. Em trabalhos futuros deverão ser investigados outros modelos de cores e novas possibilidades de combinar os resultados de detecção de bordas com estas novas componentes de cores, inclusive combinações não lineares destes resultados.

\section{REFERÊNCIAS}

BOAVENTURA, I. A. G.; GONZAGA, A. Método de avaliação de detector de bordas em imagens digitais. In: WORSKHOP DE VISÃO COMPUTACIONAL, 5., 2009. São Paulo. Anais [...]. São Paulo: Universidade Presbiteriana Mackenzie, 2009.

CAMPBELL, J. B.; WYNNE, R. H. Introduction to remote sensing. 5. ed. [S.I.]: Guilford Publications, 2011.

CANNY, J. A Computational Approach to Edge Detection, IEEE Trans. Pattern Analysis and Machine Intelligence, 1986. https://doi.org/10.1109/TPAMI.1986.476785 $\underline{1}$

CORKE, P. Robotics, vision and control: fundamental algorithms in MATLAB. 2. ed. [S.I.]: Springer Tracts in Advanced Robotics 2017. https://doi.org/10.1007/978-3-319$\underline{54413-7}$

GOMES J.; VELHO, L. Computação gráfica: Imagem. Rio de Janeiro: IMPA/SBM, 1994.
CRULHAS, J. P. R.; ARTERO, A. O., PITERI, M. A.; SILVA, F. A.; PEREIRA, D. R.; ELER, D. D., ALBUQUERQUE, V. H. C., Blank Spots Identification on Plantations. IEEE Latin America Transactions,v. 16, n. 8, p. 21152121, 2018. https://doi.org/10.1109/TLA.2018.8528224

J. D. Thematic mapping from satellite imagery: a guidebook. 1.ed. [S.I.]: Pergamon, 1994. 296,

GAVRILOVA, M.L.; MONWAR, M. Multimodal biometrics and intelligent image processing for security systems. Portland, OR: Scopus, 2013. 232 p. https://doi.org/10.4018/978-14666-3646-0

GONZALES, R.; WOODS, R. Processamento digital de imagens. São Paulo: Edgard Blücher, 1999.

JIANWEI, W. An improved method of color image edge detection based on one order gradient operator. International Journal of Hybrid Information Technology, v. 6, n. 5, p. 151-162, 2013.

https://doi.org/10.14257/ijhit.2013.6.5.14

MCANDREW, A. An introduction to digital image processing with Matlab, Melbourn, 2004.

MCAULIFFE, M. J.; LALONDE, F. M.; MCGARRY, D.; GANDLER, W.; CSAKY, K., TRUS, B. L. Medical Image Processing, Analysis and Visualization in clinical research. IEEE SYMPOSIUM ON COMPUTER-BASED MEDICAL SYSTEMS., 14, CBMS 2001, , Proceedings [...]. Bethesda, MD, USA, 2001, pp. 381-386, https://doi.org/10.1109/CBMS.2001.941749

OTHMAN, Z.; HARON, H.; KADIR, M. R. A Comparison of Canny and Sobel Edge Detection in MRI Images. Comput. Sci. Biomech., p. 133-136, 2009, 
PARKER, J. R. Algorithms For Image Processing and Computer Vision. New York: John Wiley \& Sons, 1996.

SANG, H.; MA, Y.; HUANG, J. Robust Palmprint Recognition Base on Touch-Less Color Palmprint Images Acquired. Journal of Signal and Information Processing, v. 4, n. 2, p.1-6, 2013.

SILVA, W. D. F. D. Modelos de representação de cores, 1995. Disponível em: http://www. dca.fee.unicamp.br/ lotufo/ Courses/ia-6361995/well/trabalho.html. Acesso em: 26 maio 2018.

SOUTO, R. P. Segmentação de imagem multiespectral utilizando-se 0 atributo matiz. São José dos Campos: INPE, 2000.
Disponível em: www.obt.inpe.br/pgsere/ Souto-RP-2000/publicacao.pdf. Acesso em: 16 abr. 2018.

$X U, H . ;$ ZHANG, Y.; ZHAO, H. Edge detection of color image using mathematical morphology in HSV color space. 2. ed. International Conference on Computer Science and Network Technology, 2012. https://doi.org/10.1109/ICCSNT.2012.652633 $\underline{5}$

ZHU, S-Y.; PLATANIOTIS, K. N.; VENETSANOPOULOS, A. N. Comprehensive analysis of edge detection in color image processing. Optical Engineering, v. 38, n.. 4, 1998. https://doi.org/10.1117/1.602105 